\title{
Inhalation Powder, Hard Capsule Dosage Form
}

National Cancer Institute

\section{Source}

National Cancer Institute. Inhalation Powder, Hard Capsule Dosage Form. NCI

Thesaurus. Code C149579.

Solid single-dose preparation intended for inhalation use, consisting of one or more powders of solid active substance(s) enclosed in a hard capsule. The capsule is loaded into a dry-powder inhaler to generate an aerosol. 